Progress in the management of solid tumours

Series editor: Mr Colin D fohnson, Department of Surgery, Southampton General Hospital, Southampton SO9 4WX, UK

\title{
Testicular carcinoma
}

\author{
Ann O'Callaghan, Graham M Mead
}

\begin{abstract}
Summary
Testicular cancer is the commonest malignancy in young males and its incidence has more than doubled in the last 25 years. For clinical purposes, two tumour types are identified, seminoma and non-seminoma germ cell tumours (loosely known as teratomas). Stage I disease is confined to the testes and is managed surgically, with adjuvant chemotherapy or radiotherapy as appropriate. Cisplatin-based chemotherapy is the cornerstone of treatment for metastatic disease, with cure rates exceeding $80 \%$. Early diagnosis and cure should be the aim in all patients. To this end, those with testicular symptoms should be evaluated promptly by ultrasound, and in young male patients presenting with the clinical picture of metastatic disease, germ cell tumour should top the list of differential diagnoses.
\end{abstract}

Keywords: testicular cancer, germ cell tumours

\begin{tabular}{|l|}
\hline Testicular tumours \\
\hline Germ cell tumours \\
— seminoma $(40 \%)$ \\
- teratoma $(50 \%)$ \\
Gixed $(10 \%)$ \\
Gondal stromal tumours \\
- Sertoli cell tumour \\
Teydig cell tumour \\
Sarcoular lymphoma \\
\hline
\end{tabular}

Box 1

CRC Wessex Medical Oncology Unit, Royal South Hants Hospital, Brintons Terrace, Southampton SO14 OYG, UK

A O'Callaghan

GM Mead

Accepted 17 July 1996
The cure rate for testicular cancer is now over $90 \%$, this represents dramatic progress when it is considered that metastatic disease was almost universally fatal 25 years ago. Although they account for only $1 \%$ of cancers in males, testicular tumours assume a disproportionate importance because they are the commonest cancers in the 15-34-year-old age group.

\section{Incidence}

The incidence of testicular cancer has risen sharply throughout the Western world in this century and continues to rise at the present time. There are approximately 1250 cases diagnosed in the UK each year. In 1970 there were 2.7 cases per 100000 in England and Wales and latest available figures from 1989 show an incidence of 5.1 per $100000 .{ }^{1}$ The majority of testicular cancers are germ cell tumours with other types accounting for less than $5 \%$ of cases (box 1).

\section{Aetiology and epidemiology}

The causes of the increasing incidence of testicular cancer are poorly understood and though many aetiological factors have been proposed, only a history of developmental urogenital abnormalities is well established. ${ }^{2}$ Whereas one in 450 males will develop testicular cancer, $1-2 \%$ of boys with a history of cryptorchidism will do so. However, only $10 \%$ of testicular cancers arise in maldescended testicles and correction by orchidopexy before 10 years of age may eliminate this excess risk. The contralateral testicle is also at risk and in $25 \%$ of cases with a history of cryptorchidism, the tumour arises in the apparently normal side. Bilateral tumours at presentation are uncommon (1\%), although the risk of subsequent contralateral disease is $2-3 \%$; this can be recognised by finding carcinoma-in-situ of the contralateral testis on biopsy. ${ }^{3}$

\section{Pathology}

Germ cell tumours develop from multipotent germ cells and although they most commonly arise in the testes $(90 \%)$ they may originate from residual midline germinal elements in the mediastinum, retroperitoneum or supra-sellar area. About $40 \%$ of testicular germ cell tumours are seminomas, $50 \%$ are nonseminomatous, loosely known as teratomas, and in approximately $10 \%$ a mixture of these elements can be identified. Two classification systems are commonly used, that of the World Health Organisation (WHO) and that devised by the British Testicular Tumour $\mathrm{Panel}^{4}$ (box 2).

Grossly, seminoma is usually a well-circumscribed solid mass without haemorrhage or necrosis (figure 1). In contrast, malignant teratomas are a histologically diverse set of tumours. They often have both solid and cystic components with areas of haemorrhage and necrosis (figure 2). These comprise a mixture of benign (teratoma differentiated) and malignant elements. Differentiated or mature teratoma has tissues arising from the three developmental layers (endoderm, ectoderm or mesoderm) in any combination. The malignant elements may be either yolk sac tumour, embryonal carcinoma (malignant teratoma, undifferentiated) or choriocarcinoma (malignant teratoma, trophoblastic). Pure choriocarcinomas are rare, accounting for less than $0.5 \%$ of all germ cell tumours. Pure embryonal carcinoma accounts for up to $10 \%$ of cases. Careful histological examination of the tumour is required to recognise all elements of the combination. Some specific features of the primary tumour are associated with a high risk of metastasis ${ }^{5}$ (box 3 ).

At a molecular level little is known about these tumours but many have complex karyotypes, with a hypo or hyper-triploid DNA index. The commonest 


\begin{tabular}{|ll|}
\hline \multicolumn{2}{|c|}{$\begin{array}{l}\text { Classification of testicular } \\
\text { germ cell tumours }\end{array}$} \\
\hline $\begin{array}{l}\text { British testicular } \\
\text { tumour panel }\end{array}$ & WHO \\
- seminoma: & seminoma: \\
classical & typical \\
spermatocytic & spermatocytic \\
- malignant & non-seminomatous \\
teratoma: & germ cell tumour: \\
undifferentiated & $\begin{array}{l}\text { embryonal } \\
\text { carcinoma }\end{array}$ \\
intermediate & $\begin{array}{l}\text { embryonal } \\
\text { carcinoma with }\end{array}$ \\
& $\begin{array}{l}\text { teratoma } \\
\text { (teratocarcinoma) }\end{array}$ \\
differentiated & teratoma, mature \\
trophoblastic & choriocarcinoma \\
yolk sac tumour & yolk sac tumour \\
\hline
\end{tabular}

Box 2

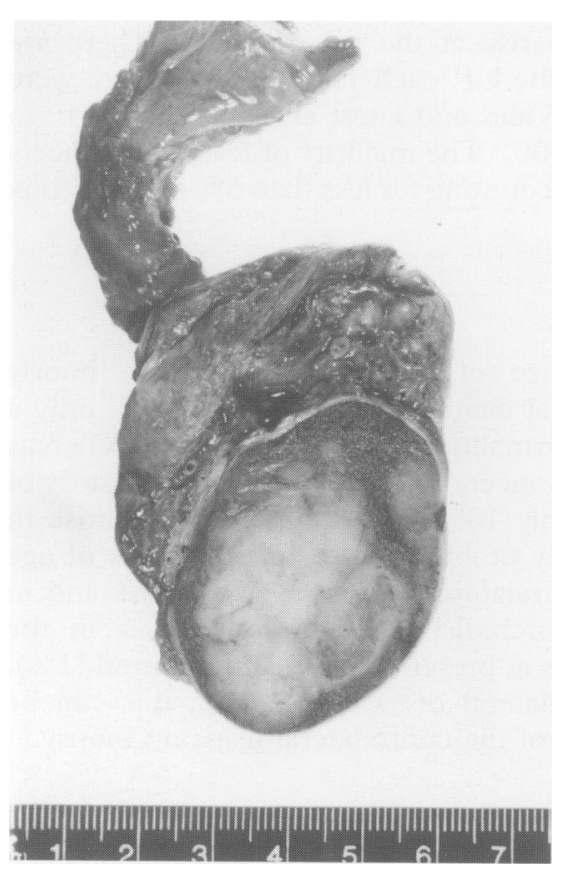

Figure 1 Testicular seminoma, a bisected orchidectomy specimen

\begin{tabular}{|l|}
\hline Histological features of non- \\
seminomatous germ cell \\
tumour associated with high \\
risk of metastases \\
\hline - invasion of testicular veins \\
- invasion of testicular lymphatics \\
- presence of undifferentiated cells \\
- absence of yolk sac elements \\
\hline
\end{tabular}

Box 3 chromosomal abnormality identified is an isochromosome of the short arm of chromosome twelve (i(12p)), seen in $90 \%$ of cases. ${ }^{6}$ This has also been identified in extra-gonadal germ cell tumours and carcinoma-in-situ but the corresponding genetic defect has not yet been identified.

\section{Tumour markers}

Tumour markers have an established role in the management of testicular cancer. The relevant markers are $\alpha$-foetoprotein, human chorionic gonadotropin, and lactate dehydrogenase. ${ }^{7}$

$\alpha$-Foetoprotein is the major serum protein of the foetus and consists of a single polypeptide chain. Its serum half-life is $5-6$ days. Elevated serum levels of this protein are not found in normal adults. $\alpha$-Foetoprotein is raised in a variety of hepatic conditions, both benign and malignant, but in a young male patient an elevated level is almost diagnostic of malignant teratoma. It is produced by a yolk sac tumour and up to $90 \%$ of tumours with yolk sac elements are associated with $\alpha$-foetoprotein elevation. If $\alpha$-foetoprotein is raised in patients with histologically pure seminoma this implies the presence of yolk sac tumour and thus management is according to teratoma protocols. Human chorionic gonadotropin is a placental hormone. It is a glycoprotein composed of two subunits; the alpha subunit is common to human chorionic gonadotropin, luteinising hormone, follicle-stimulating hormone and thyroid-stimulating hormone and the beta subunit is unique and therefore usually assayed. Its half-life is $12-20 \mathrm{~h}$ and serum levels are easily quantified by radioimmunoassay. Human chorionic gonadotropin is produced by $100 \%$ of trophoblastic tumours and elevated levels in non-seminomatous germ cell tumour imply presence of trophoblastic elements. A raised human chorionic gonadotropin level is seen in about $10 \%$ of seminomas and correlates with the presence of syncytiotrophoblastic cells; it may also be raised in other poorly differentiated malignancies, most commonly of gastrointestinal origin.

In the context of non-seminomatous germ cell tumour, $\alpha$-foetoprotein and human chorionic gonadotropin levels when raised are reliable markers of tumour burden, prognosis, and response to treatment. Elevation from a previously normal level implies relapse. The degree of elevation of lactate dehydrogenase has also proven to be a reliable prognostic indicator in germ cell tumours and a rising level in a patient who has achieved remission may herald relapse. $^{8}$

\section{Presentation}

The majority of patients present with symptoms referable to the affected testicle. Testicular swelling is usually present and may or may not be painful. Acute pain may result from torsion, haemorrhage or infarction of the tumour. Some will present with symptoms and signs of metastatic disease; back pain caused by retroperitoneal disease or respiratory symptoms secondary to lung metastases or mediastinal disease (figure 3 ). Though the primary tumour may not be obvious it can usually be identified on ultrasound examination of the scrotum. In those with human chorionic gonadotropin-secreting tumours gynaecomastia may be the main complaint.

\section{Evaluation}

All patients presenting with a testicular mass or persistent testicular aching/pain should have a testicular ultrasound examination and blood taken for tumour marker measurement. If suspicious features are seen at ultrasound the patient should proceed to surgical exploration and radical inguinal orchidectomy if a tumour is suspected. Needle biopsy is absolutely contraindicated, as is a transscrotal approach for orchidectomy, both procedures being associated with an increased risk of local recurrence and inguinal nodal metastases. Elevated tumour markers help confirm the diagnosis, but $15 \%$ of non-seminomatous germ cell tumours and $90 \%$ of seminomas are marker negative, and therefore a negative result should not influence the surgical decision. When extensive metastatic disease is present, grossly elevated marker levels can be taken as diagnostic and treatment should not be delayed for orchidectomy or biopsy of a metastatic site.

\section{Staging}

Seminoma spreads in a predictable fashion via lymphatics, initially to paraaortic nodes and subsequently to contiguous posterior mediastinal nodes. Non- 


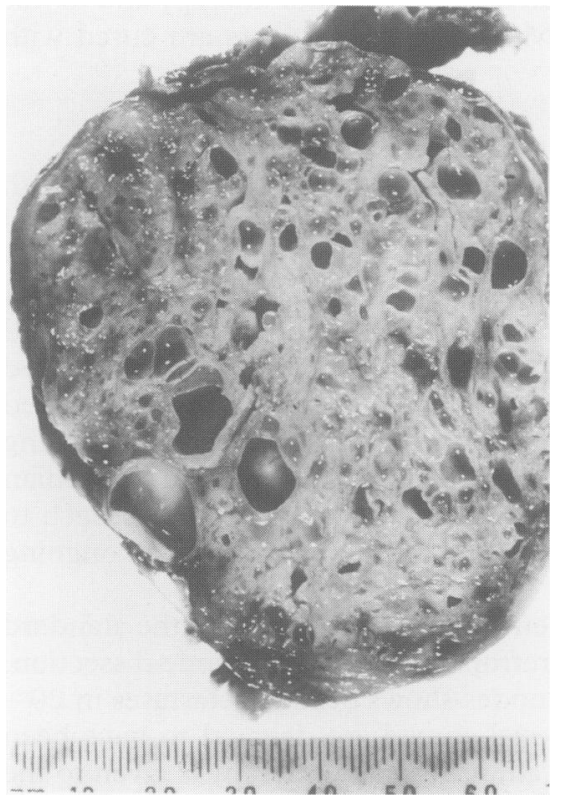

Figure 2 Testicular teratoma showing cystic and solid components seminomatous germ cell tumours may metastasise via vascular or lymphatic routes or both. The pattern of metastases is not predictable but the most common sites are retroperitoneal nodes, mediastinal and supraclavicular nodes and the lungs. Non-pulmonary visceral metastases are rare in both seminoma and teratoma and are associated with a poor prognosis. ${ }^{9}$ Choriocarcinoma generally presents with widespread haemorrhagic metastases and has a propensity for spread to the central nervous system.

In general, stage I describes disease limited to the testicle and stage II denotes intra-abdominal nodal involvement, usually subdivided according to tumour bulk. Stage III indicates nodal spread beyond the retroperitoneum, with stage IV used to denote extra-nodal disease. Staging investigations must include a chest X-ray and computed tomography (CT) of the pelvis, abdomen and thorax. Serial estimation of tumour markers following orchidectomy is mandatory and failure of markers to fall to normal is indicative of metastatic disease, even if this is not identified radiologically; this is denoted as stage Im.

\section{Management (box 4)}

\section{STAGE I SEMINOMA}

Three-quarters of patients with seminoma will present with clinical stage I disease, but a number of these will have occult retroperitoneal disease. If no further treatment is given post-orchidectomy $15-20 \%$ of these patients will relapse. This may occur up to 10 years post-diagnosis. Seminoma is an exquisitely radiosensitive disease and standard treatment for these patients has been adjuvant radiotherapy to para-aortic and ipsilateral inguinal nodes. This approach yields a $97 \%$ cure rate ${ }^{10}$ and relapsing patients are usually cured with chemotherapy. A recent randomised trial has shown that treatment of the paraaortic nodes alone is adequate, ${ }^{11}$ except in patients who have a history of previous surgery in the inguinal region of transgression of the scrotum, who are at higher risk of local relapse or inguinal node involvement. Current trials are looking at reduced-dose radiotherapy versus conventional dose. The acute toxicities of this treatment are gastrointestinal, including diarrhoea and peptic ulceration, transient oligospermia and mild myelosuppression. ${ }^{10}$ Radiotherapy is associated with an increased risk of second malignancy. Stage II patients with

Figure 3 (A) Chest X-ray at presentation of a 22-year-old with a left testicular primary tumour ( $<1 \mathrm{~cm}$ on ultrasound) and extensive intra-abdominal nodal disease. Tumour markers were grossly elevated, human chorionic gonadotropin $15600 \mathrm{IU} / 1$ (normal <4), $\alpha$ foetoprotein $1200 \mathrm{kU} / \mathrm{l}$ (normal < 10), lactate dehydrogenase 1713 IU/l (normal 200-450). Chemotherapy was not delayed for biopsy. (B) Chest X-ray of the same patient after four cycles of 'BEP' chemotherapy
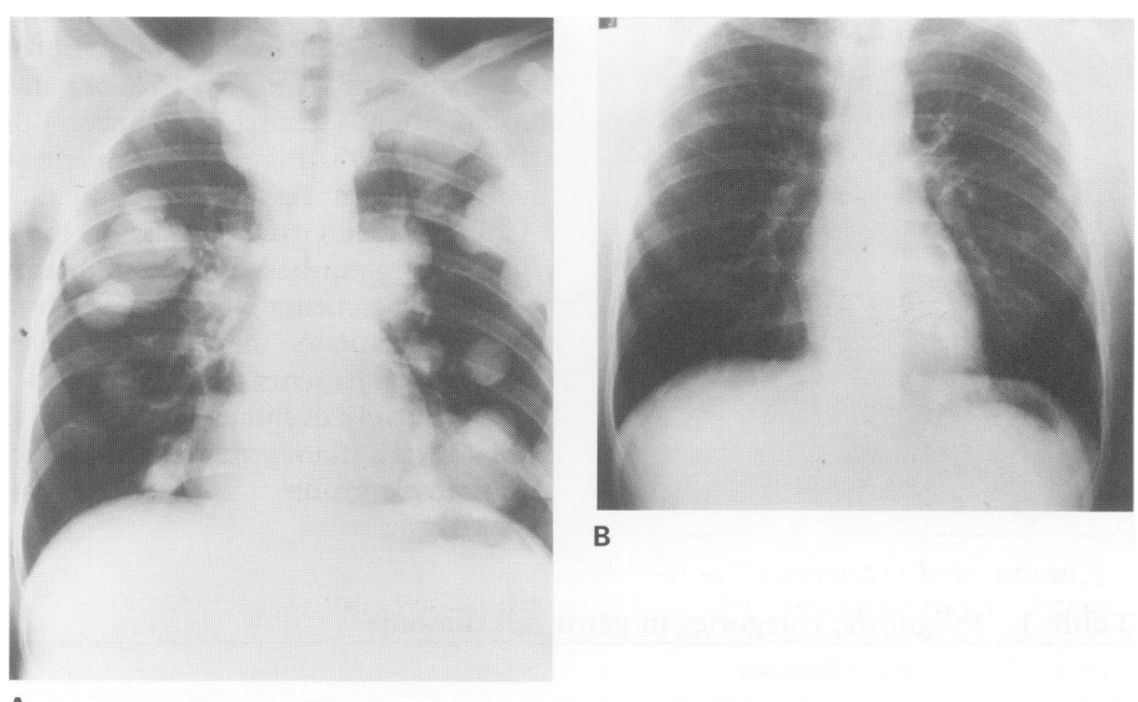

B
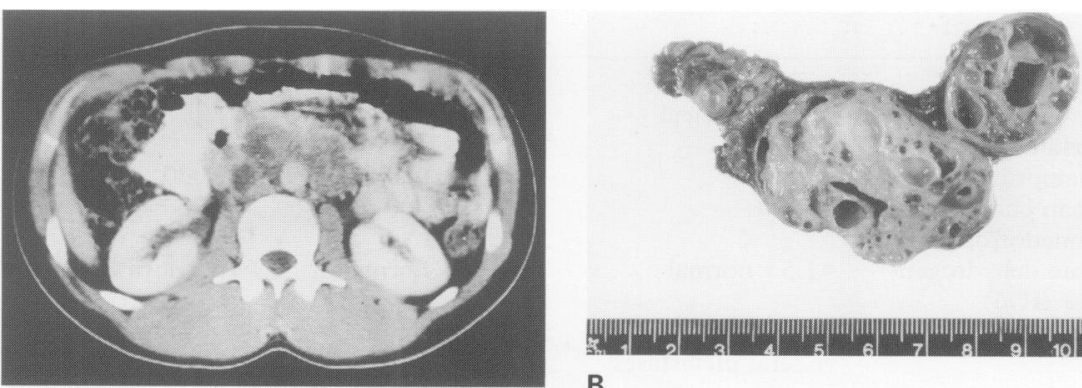


\begin{tabular}{|c|}
\hline $\begin{array}{l}\text { Management options in germ } \\
\text { cell tumours }\end{array}$ \\
\hline $\begin{array}{l}\text { Stage I seminoma } \\
\text { - adjuvant radiotherapy to para-aortic } \\
\text { nodes }\end{array}$ \\
\hline $\begin{array}{l}\text { Stage I Non-seminomatous germ cell } \\
\text { tumour } \\
\text { - watch policy } \\
\text { - short course chemotherapy } \\
\text { - retroperitoneal lymph node } \\
\text { dissection }\end{array}$ \\
\hline $\begin{array}{l}\text { Metastatic seminoma } \\
\text { - radiotherapy (low volume } \\
\text { abdominal disease) } \\
\text { - chemotherapy (bulky disease/failed } \\
\text { radiotherapy) }\end{array}$ \\
\hline $\begin{array}{l}\text { Metastatic non-seminomatous germ cell } \\
\text { tumour } \\
\text { - combination chemotherapy } \\
\text { - surgery to residual disease }\end{array}$ \\
\hline
\end{tabular}

Box 4 low volume retroperitoneal disease are also treated with radiotherapy and in this group there is a $10-15 \%$ relapse rate. Mose of these patients are cured with salvage chemotherapy.

\section{NON-SEMINOMATOUS GERM CELL TUMOUR STAGE I}

About $40 \%$ of cases of non-seminomatous germ cell tumour present with clinical stage I disease. Following orchidectomy markers return to normal levels. In $70-75 \%$ this surgery alone is curative, however, close surveillance is mandatory to detect the $25-30 \%$ who relapse, usually within one year. A number of features of the primary tumour are predictive of relapse ${ }^{5}$ (box 3 ) and in a study of over 300 cases those with three or four of these risk factors showed a $47 \%$ relapse rate at two years, while zero to two risk factors were associated with a $20 \%$ relapse rate. ${ }^{12}$ A group of 115 patients defined as high risk according to these criteria were treated with short-course chemotherapy and at median follow-up of 25 months there have been only two relapses. ${ }^{13}$ This approach to management of high-risk stage I patients is being further explored in an ongoing MRC trial.

The alternative approach to management of these patients, still the standard of care in the US, is to perform a radical retroperitoneal lymph node dissection. Histological examination of the resected nodes shows occult metastases in 20 $40 \%$ of patients. Those with minimal nodal spread are deemed to have been cured with this surgical procedure, while adjuvant chemotherapy is given to the remainder. A $10 \%$ extra-abdominal relapse rate is recorded post-surgery. In experienced hands, mortality and morbidity are low but despite nerve-sparing techniques, permanent impotence or retrograde ejaculation may occur in a significant number. In view of excellent cure rates with a watch policy/ chemotherapy approach, we see no advantage in routine use of this diagnostic/ therapeutic procedure.

\section{MANAGEMENT OF METASTATIC DISEASE}

Cisplatin-based combination chemotherapy has revolutionised the management of metastatic germ cell tumours ${ }^{14}$ and whereas 25 years ago this was an almost universally fatal malignancy, current cure rates now exceed $80 \%$. No patient with germ cell cancer, no matter how ill at diagnosis, should be considered beyond prospect of a cure. However, all these patients should be managed in a specialised unit where medical, surgical, radiological and nursing staff are familiar with dealing with the particular problem posed by this patient group.

Sixty per cent of patients with non-seminomatous germ cell tumour have metastases at diagnosis; $15 \%$ of patients with seminoma have metastatic disease of an extent (stage 11c or higher) that requires treatment with chemotherapy. Prior to 1995 there was no internationally agreed prognostic classification, a situation that has been rectified by the International Germ Cell Cancer Collaborative Group. Based on the analysis of records of 3433 patients treated with cisplatin-based chemotherapy (before 1990) a simple, universally applicable schema was drawn up which divided non-seminomatous germ cell tumour patients into good, intermediate and poor prognosis groups and seminoma patients into good and intermediate prognosis groups ${ }^{9}$ (table 1). Prospectively evaluated, these groupings behaved as predicted ${ }^{9}$ (table 2 ), and thus future management of germ cell malignancies should be tailored to each prognostic group.

Table 1 Prognostic categories in germ cell tumours

\begin{tabular}{|c|c|c|c|c|c|}
\hline & \multicolumn{3}{|l|}{ Teratoma } & \multicolumn{2}{|l|}{ Seminoma } \\
\hline & $\begin{array}{l}\text { Good prognosis } \\
\text { Must fulfil all } \\
\text { criteria below }\end{array}$ & Intermediate prognosis & $\begin{array}{l}\text { Poor prognosis } \\
\text { Any of these } \\
\text { features implies } \\
\text { poor prognosis }\end{array}$ & $\begin{array}{l}\text { Good prognosis } \\
\text { Must fulfil all } \\
\text { criteria below }\end{array}$ & $\begin{array}{l}\text { Poor prognosis } \\
\text { Any of these } \\
\text { features implies } \\
\text { poor prognosis }\end{array}$ \\
\hline $\begin{array}{l}\text { Primary } \\
\text { Markers }\end{array}$ & $\begin{array}{l}\text { testis or } \\
\text { retroperitoneal }\end{array}$ & $\begin{array}{l}\text { testis or } \\
\text { retroperitoneal }\end{array}$ & mediastinal & any site & any site \\
\hline$\alpha$-foetoprotein $(\mathrm{kU} / \mathrm{l})$ & $<1000$ & $1000-10000$ & $>10000$ & $\mathrm{n} / \mathrm{a}$ & $\mathrm{n} / \mathrm{a}$ \\
\hline $\begin{array}{l}\text { human chorionic } \\
\text { gonadotropin (IU/l) }\end{array}$ & $<5000$ & $5000-50000$ & $>50000$ & $\mathrm{n} / \mathrm{a}$ & $\mathrm{n} / \mathrm{a}$ \\
\hline $\begin{array}{l}\text { lactate dehydrogen- } \\
\text { ase (IU/l) }\end{array}$ & $<1.5 \times$ normal & $1.5-10 \times$ normal & $>10 \times$ normal & $\mathrm{n} / \mathrm{a}$ & $\mathrm{n} / \mathrm{a}$ \\
\hline Metastases & $\begin{array}{l}\text { no non-pulmonary } \\
\text { visceral metastases }\end{array}$ & $\begin{array}{l}\text { no non-pulmonary } \\
\text { visceral metastases }\end{array}$ & liver, brain, bone & $\begin{array}{l}\text { no non-pulmonary } \\
\text { visceral metastases }\end{array}$ & liver, brain, bone \\
\hline
\end{tabular}


Table 2 Metastic germ cell tumours: distribution and survival

\begin{tabular}{lll}
$\begin{array}{l}\text { Prognostic } \\
\text { group }\end{array}$ & $\begin{array}{l}\text { Patients } \\
\text { in group (\%) }\end{array}$ & $\begin{array}{l}\text { Three-year } \\
\text { survival (\%) }\end{array}$ \\
\hline $\begin{array}{lll}\text { Teratoma } \\
\text { good }\end{array}$ & 56 & 92 \\
intermediate & 28 & 81 \\
poor & 16 & 50 \\
Seminoma & & \\
good & 90 & 86 \\
intermediate & 10 & 77 \\
\hline
\end{tabular}

\begin{tabular}{|l|}
\hline $\begin{array}{l}\text { Cytotoxic drugs used in } \\
\text { treatment of germ cell } \\
\text { tumours }\end{array}$ \\
\hline - cisplatin \\
- etoposide \\
- bleomycin \\
- vinblastine \\
- incristine \\
- mesfamide \\
- paclitaxex \\
\hline
\end{tabular}

Box 5
A number of chemotherapeutic agents are active in germ cell tumours (box 5). All regimens are cisplatin based, and standard therapy combines this with etoposide and bleomycin ${ }^{14}$; 'BEP' denotes this combination. Standard treatment for good prognosis disease in which expectation of cure is over $90 \%$ is four courses of BEP given at three-weekly intervals. Given that the majority of such patients are destined to be long-term survivors, the current challenge is to maintain the efficacy of treatment while attempting to reduce toxicity. ${ }^{15}$ Current trials are aimed at fine-tuning these treatments to the scheme most acceptable to patients, without compromise of cure rates. Carboplatin, a less emetogenic platinum drug, has proven inferior to cisplatin in randomised trials and has no place in first-line management of non-seminomatous germ cell tumours. ${ }^{16,17}$

Large randomised trials in poor risk patients have not identified a more efficacious combination than BEP. Use of haemopoietic growth factors (granulocyte colony-stimulating factors) throughout chemotherapy, to maintain blood counts and thus avoid dose reductions and treatment delay, has failed to improve cure rates. ${ }^{18}$ Many trials looking at more intensive chemotherapy regimes in those predicted to have a poor outcome are ongoing. These involve escalated doses of chemotherapy usually supported by peripheral blood stem cells to shorten neutropenic time; results from some centres look promising. ${ }^{19}$

\section{CHEMOTHERAPY FOR SEMINOMA}

Chemotherapy is used in seminoma patients with stage IIc disease (abdominal mass $>5 \mathrm{~cm}$ ) or higher and in those who have failed radiotherapy. The twodrug combination, cisplatin plus etoposide, is frequently used, as is BEP and $90 \%$ failure-free survival can be expected. Single agent carboplatin may be a preferred less toxic option in certain circumstances but failure-free survival rates fall to $80 \% .^{20}$

\section{Post-chemotherapy evaluation}

During chemotherapy, markers are checked regularly and should fall to normal levels as disease responds. Radiological re-evaluation post-chemotherapy is with CT scans of abdomen and chest. In non-seminomatous germ cell tumour, masses identified pre-treatment may resolve completely, persist unchanged or even increase in size (the growing teratoma syndrome). Complete removal of all residual abnormalities is recommended and should be performed by specialist surgeons experienced in the management of these tumours. Residual masses may contain necrotic or fibrotic tissue, teratoma differentiated (mature teratoma) or malignant tissue or a mixture of all these elements (figure 4). Fortunately, persistent cancer is rare $(5-10 \%)$ but if present, further chemotherapy is required. ${ }^{21}$ Mature teratoma, if left in situ, may grow and impinge on or invade normal organs, may de-differentiate, or may become a site of a second malignancy.

Masses commonly remain after treatment of bulky seminoma and in this situation they can safely be observed on serial scans and are usually seen to shrink over time and subsequently calcify. A growing mass in the context of pure seminoma indicates relapsing disease.

\section{Disease relapse}

While first-line treatment is fortunately curative for many, up to $50 \%$ in the poor prognosis category will progress or relapse. Salvage chemotherapy followed by surgery as appropriate is associated with long-term failure-free survival rates of $20-25 \%$. Gonadal primaries are in general more responsive but improving results are now being seen in mediastinal disease as well. Consolidation of salvage treatment with high-dose chemotherapy, supported by peripheral blood stem cell or autologous bone marrow transplant probably increases failure-free survival rates to $26-44 \%$. Cisplatin-resistant disease, defined as disease progressing within one month of administration of cisplatin is associated with a very poor outlook but with high-dose treatment and peripheral blood stem cell or autologous bone marrow transplant about $10 \%$ failure-free survival has been recorded. ${ }^{22}$ Paclitaxel, a relatively new chemotherapeutic agent, is showing promising activity in these tumours in phase II trials. ${ }^{23}$

\section{Treatment toxicities}

The acute toxicities of treatment include nausea, vomiting, malaise, myelosuppression and alopecia. These are transient and usually the patient has fully recovered and reports full resumption of normal activities within six months of. 
starting treatment. 'Bleomycin lung' describes a fibrotic lung disease which is a rare but life-threatening complication of administration of this drug. As most patients are long-term survivors there has been an opportunity to observe the long-term effects of these treatments. Psychosexual problems are uncommon but usually respond to counselling. Fertility is adversely effected by chemotherapy but usually returns to normal in those who had normal spermatogenesis prior to diagnosis. Despite this, sperm banking should be offered to those who are fit enough prior to commencing chemotherapy. High tone hearing loss secondary to cisplatin may be permanent and a subclinical reduction in renal function (averaging about 10\%) can be documented. Etoposide is known to be leukaemogenic but this effect is associated with higher doses than are routinely used in testicular cancer.

\section{Screening}

Testicular cancer affects one in 450 males, with a median age of presentation of teratoma of 29 years and seminoma slightly higher at 37 years. This frequency is too low to justify screening in the general population, but heightening of awareness and education of the male population is vital, so that they can learn testicular self-examination and, in particular, be aware of the significance of symptoms and signs should they develop. Routine follow-up examinations of those with a history of cryptorchidism is not generally recommended. From a medical perspective it is important to remember and emphasise that testicular examination should be considered an essential part of abdominal examination. A fast-track referral system should be available to general practitioners allowing access to scrotal ultrasound and surgical assessment of those presenting with testicular symptoms. Earlier diagnosis may increase the numbers picked up with early stage disease and thus improve overall cure rates. At the other end of the spectrum, in any young ( $<50$ years) male patient with metastatic disease, germ cell cancer should be considered and appropriate investigations undertaken, as no matter how sick, there is always the prospect of a cure if this proves to be germ cell malignancy.

\section{Future directions}

Although enormous progress has been made in the management of germ cell malignancies, the aetiology of these tumours is poorly understood. Earlier diagnosis and use of short-course chemotherapy in high-risk stage I nonseminomatous germ cell tumours may improve patient outcome. International agreement of prognostic groupings will aid the evaluation of new agents and dose-intense regimens and hopefully lead to improved survival.

1 Cancer statistics registrations, England and Wales 1989. London: Office of Population of Census and Surveys. Series MB1 no 29, 1994.

2 Forman D, Pike MC, Davey G, et al. Aetiology of testicular cancer: association with congenital abnormalities, age at puberty, infertility, and exercise. BMF 1984; 308: 1393 -9.

3 Von de Masse H, Rorth M, Walborn-Jorgessen $\mathrm{S}$, et al. Carcinoma in situ of the contralateral A study of 27 cases in 500 patients. $B M \mathcal{F} 1986$; 293: $1398-401$.

4 True LD, Rosai J. Tumours of the testis. In: Mc Gee JO'D, Isaacson PG, Wright NA, eds. Oxford textbook of pathology. Oxford: Oxford University Press, 1992; pp 1554-62.

5 Freedman LS, Parkinson MC, Jones WG, et al. Histopathology in the prediction of relapse of patients with stage I testicular teratoma treated by orchidectomy alone: a Medical Research Council collaborative study. Lancet 1987; 8554: 294-8.

6 Rodriguez E, Mathew S, Reuter V, Ilson DH, Bosl GJ, Chaganti RSK. Cytogenetic analysis of 124 prospectively ascertained male germ cell tumours. Cancer Res 1992; 52: 2285-91.

7 Bates SE, Longo DL. Use of serum markers in cancer diagnosis and management. Semin Oncol 1987; 14: 102-38.

8 Mead GM, Stenning SP, Parkinson MC, et al. The second Medical Research Council study of The second Medical Research Council study of
prognostic factors in non-seminomatous germ prognostic factors in non-seminomatous germ
cell tumours. $₹$ Clin Oncol 1992; 10: 85-94.

9 Mead GM, Stenning SP, Cook P, et al. International consensus on germ cell classification. A prognostic factor based staging system for metastatic germ cell cancers. F Clin Oncol 1997 14: $1106-13$.
10 Hamilton C, Horwich A, Easton D, et al. Radiotherapy for stage I seminoma testis: results of treatment and complications. Radiother Oncol 1986; 6: 115-20.

11 Fossa SD, Aass N, Kaalhus O. Radiotherapy for testicular seminoma stage 1: treatment results and long term post-irradiation morbidity in 365 patients. Int $\mathcal{f}$ Radiat Oncol Biol Phys 1989; 16: patients.

12 Read G, Stenning SP, Cullen MH, et al. Medical Research Council prospective study of surveillance for stage I testicular teratoma. $₹$ Clin Oncol lance for stage I tes
1992; 10: $1762-8$.

13 Cullen MH, Stenning SP, Parkinson MC, et al. Short course adjuvant chemotherapy in high risk stage I non-seminoma germ cell tumour of the testis. A Medical Research Council report. $f$ Clin Oncol 1997; 15: 594-603.

14 Einhorn LH. Treatment of testicular cancer: a new and improved model. $\mathcal{f}$ Clin Oncol 1990; 8: $1977-81$.

15 Garrow GC, Johnson DH. Treatment of good risk metastatic testicular cancer. Semin Oncol 1992; 19: 159-65.

16 Bajorin DF, Sarosdy MF, Pfister DG, et al. Randomised trial of etoposide and cisplatin versus etoposide and carboplatin in patients with versus etoposide and carboplatin in patients with tional study. F Clin Oncol 1993; 11: 598-606.
17 Kaye SB, Mead GM, Fossa S, et al. An MRC/ EORTC randomised trial in poor prognosis metastatic teratoma, comparing BEP with BOP/VIP (abstract). Proc ASCO 1995; 14: 246.

18 Cullen M, De Wit R, Bodrogi I, et al. An MRC/ EORTC randomised trial in poor prognosis metastatic teratoma, comparing treatment with without filgrastim (G-CSF) (abstract). Proc ASCO 1995; 14: 245 .

19 Bokemeyer C, Harstrick A, Ruther U, et al. Sequential high-dose VIP-chemotherapy plus peripheral blood stem cell (PBSC) support in peripheral blood stem cell (PBSC) support in
advanced germ cell cancer (abstract). Proc advanced germ cell

20 Horwich A, Dearnaley DP, Duchesne GM, et al. Simple non-toxic treatment of advanced metastatic seminoma with carboplatin. $\mathcal{f}$ Clin Oncol 1989; 7: 1150-6.

21 Jansen RLH, Sylvester R, Sleyfer DT, et al. Long term follow up of non-seminomatous testicular cancer patients with mature teratoma or carcinoma at postchemotherapy surgery. Eur $7 \mathrm{Cancer}$ 1991; 27: 695-8.

22 Horwich A. Salvage chemotherapy of germ cell tumours. Br $\mathcal{F}$ Cancer 1995; 71: $901-3$.

23 Motzer RJ, Chou TC, Schwartz L, et al. Paclitaxel in germ cell cancer. Semin Oncol 1995; 22(supp 6:) $12-5$. 